The Israeli-Palestinian Conflict

2 Terrorist Attacks, Military Retaliation;

Bush Calls for New Palestinian Leadership

Crisis in South Asia

148 Indian and Pakistani War Rhetoric, Troop Moblizations, Bring Sub-Continent Close to Armed Conflict

Counter-Terrorism

172 Bush Administration Begins to Redirect Focus of War on Terrorism Toward Iraq

\title{
Arms Control
}

221 Bush-Putin Summit Yields Major Agreement on Reductions in Strategic Nuclear Weapon Stockpiles

Carter Visits Cuba

234 Jimmy Carter Undertakes Historic Visit to Cuba

244 List of Documents

247 Index 